\title{
Expression of Cytokine Receptors by Human Cord Blood Lymphocytes: Comparison with Adult Blood Lymphocytes
}

\author{
H. ZOLA, M. FUSCO, P. J. MACARDLE, L. FLEGO, AND D. ROBERTON \\ Child Health Research Institute and Flinders University, Adelaide [H.Z., M.F.], Department of Clinical \\ Immunology, Flinders Medical Centre [P.J.M., L.F.], and Department of Paediatrics, Adelaide University \\ and Adelaide Women's and Children's Hospital, Adelaide, Australia [D.R.]
}

\begin{abstract}
The expression of receptors for several cytokines (IL 2, IL-4, IL-6, IL-7, tumor necrosis factor, and interferon- $\gamma$ ) was examined in human cord blood cells in comparison with adult blood cells. A previously described high sensitivity immunofluorescence procedure was used to render the low levels of receptor measurable. Cord blood lymphocytes expressed measurable levels of most cytokine receptors, but expression tended to be lower than in adult blood cells. Examination of different lymphocyte subpopulations revealed a complex pattern with some cell types expressing particular receptors equivalent to adult levels. Cord and adult blood monocytes expressed similar cytokine receptor profiles. Receptor expression in cord lymphocytes could be regulated by activation. The results provide indications as to the relative activities of different cytokines in the development of the immune system in the neonate. (Pediatr Res 38: 397-403, 1995)

\author{
Abbreviations \\ CD4 (CD8 etc.), cell marker identified by MAb given a \\ "cluster of differentiation" designation by the Leukocyte \\ gp130, glycoprotein of molecular mass $130 \mathrm{kD}$ \\ IFN- $\gamma$, interferon- $\gamma$ \\ IL-2R (4R etc.), IL-2 receptor (IL-4 receptor etc.) \\ LGL, large granular leukocyte \\ p55 (p75 etc.), protein of molecular mass $55 \mathrm{kD}$ (75 kD etc.) \\ PE, phycoerythrin \\ PE-SA, phycoerythrin-conjugated streptavidin \\ PHA, phytohemagglutinin \\ SA, streptavidin \\ TNF, tumor necrosis factor \\ TNFR, tumor necrosis factor receptor
} Differentiation Antigens Workshops
\end{abstract}

The neonatal immunologic repertoire has a number of deficiencies in functional terms as well as reflecting a lack of previous antigenic exposure. Some protection from infection is afforded during the first weeks of life by transplacentally transmitted maternal IgG antibody and by immunologic factors in breast milk. Development of immunologic memory is a postnatal phenomenon that remains incompletely understood, as does the the development of tolerance to a wide range of environmental antigens to which the human infant is exposed in the early weeks of life. There are aspects of lymphocyte function which remain immature during the early part of infancy, and relatively little is known about the role of cytokines and cytokine receptors in the maturation of immune responsiveness in early childhood.

Cytokines control many of the reactions that constitute the immune response. Lymphocytes taken from the peripheral

Received April 18, 1994; accepted April 27, 1995.

Correspondence: Prof. H. Zola, Child Health Research Institute, Women's and Children's Hospital, 72 King William Rd., North Adelaide, South Australia 5006, Australia

Supported by a research grant from the Chanel 7 Children's Research Foundation, South Australia. blood of adults express receptors for a variety of cytokines. IL-6R is found on CD4-positive T cells (1), IL-2Rp55 chain on $B$ cells and CD4 cells $(2,3)$, IL-2Rp75 predominantly on CD8 cells and LGL $(4,5)$, IL-4R on a subset of B cells $(6)$, and the p75 TNFR predominantly on CD45R0-positive CD4 T cells (7). If staining methods of adequate sensitivity are used, these receptors can be demonstrated on lymphocytes and monocytes taken directly from blood, without the need for in vitro activation. However, activation increases the expression of some of these receptors, in some cases dramatically. This suggests that these particular cytokines mediate "downstream" functions on activated cells (for example proliferation), and that expression of the corresponding cytokine receptors may be used as an indicator of activation. On the other hand, because some cytokines mediate the maturation of lymphoid precursors, expression of some cytokine receptors may be expected on cells that have not been activated.

It is of interest to examine the expression of cytokine receptors on cord blood lymphocytes for two main reasons. First, these cells come from an immunologically inexperienced donor (the fetus), and differences between cord and adult cells 
should therefore provide clues as to which receptors are expressed as a result of immune activation. Second, lack of cytokine receptor expression may underlie some disorders in maturation of the immune system, and it will be essential to know what cytokine receptors are expressed on normal cord lymphocytes if we are to investigate possible deficits in immune deficient patients. The recent demonstration that lack of the IL-2R $\gamma$-chain is the genetic defect in X-linked severe combined immune deficiency (8) is a clear, but perhaps extreme, example of cytokine receptor defects; it is possible that changes in levels of expression (as opposed to mutation or complete absence) may be responsible for more subtle immunologic deficiencies.

\section{METHODS}

\section{Cells}

Peripheral blood was taken from healthy laboratory staff and was stored into preservative-free heparin. Cord blood from healthy full-term neonates was obtained by draining blood from the cord and mixing with preservative-free heparin as soon as possible. Any samples showing traces of clotting were not used. Mononuclear cells were obtained from peripheral and cord blood by centrifugation over Ficoll/hypaque. All blood samples were obtained with informed consent, and procedures, information sheets, and consent forms were approved by the Flinders Medical Centre Clinical Investigation Committee and the Research and Ethics Subcommittee of the Queen Victoria Hospital (Women's and Children's Hospital); the decisions of both committees are governed by the Declaration of Helsinki.

$M A b$. The MAb against cytokine receptors used in this study are tabulated in Table 1 . Some of these antibodies were available as part of the Vth International Leukocyte Differentiation Antigens Workshop (9, 10). Fluorescein-conjugated CD3, CD19, CD4, and CD8 were obtained from Becton Dickinson, San Jose, CA, and Silenus Laboratories, Melbourne.

Immunofluorescence and flow cytometry. Immunofluorescence staining was carried out by the high sensitivity procedure as described in detail elsewhere (11). In outline, the method depends on the use of three layer staining, with the MAb being detected by biotinylated anti-mouse Ig which is in turn detected by PE-SA. It is essential to use reagents which have been selected for maximum sensitivity, because biotinylated antimouse Ig reagents and PE-SA reagents vary greatly in the

Table 1. Monoclonal antibodies against cytokine receptors

\begin{tabular}{lrlll}
\hline $\begin{array}{c}\text { Cytokine } \\
\text { receptor }\end{array}$ & CD no. & Antibody & \multicolumn{1}{c}{ Origin/reference } & Isotype \\
\hline IL-2Rp55 & 25 & 7 G7B6 & Rubin et al. $(23)$ & G2a \\
IL-2Rp75 & 122 & Mik $\beta-1$ & Tsudo et al. $(24)$ & G2a \\
IL-4R & w124 & M57 & Immunex $(25)$ & G1 \\
IL-6R & 126 & MT18 & Hirata et al. $(26)$ & G2b \\
IL-6R & 126 & M37 & Brochier/LT5* & M \\
IL-6Rgp130 & 130 & AM64 & Taga et al. (27) & G \\
IL-7R & w127 & M20 & Immunex/LT5* & G1 \\
TNFRp55 & $120 \mathrm{a}$ & htr9 & Brockhaus et al. (28) & G1 \\
TNFRp75 & $120 b$ & utr1 & Brockhaus et al. (28) & G1 \\
IFN- $\gamma$ R & w119 & GlR208 & Schreiber/LT5* & G1 \\
\hline
\end{tabular}

* LT5: Leucocyte Differentiation Antigens 5th Workshop $(9,10)$. strength of signal produced. For two-color fluorescence, the unlabeled MAb was added first, followed, after incubation and washing, by biotinylated horse anti mouse Ig. Conjugated (fluoresceinated) antibody against CD19, CD3, CD4, or CD8 was added together with the PE-SA, after blocking available sites on the anti-mouse Ig using normal mouse Ig (11). Fluorescence was analyzed on a FACScan instrument (Becton Dickinson, San Jose, CA), using standard instrument parameters and Lysis II software. Monocytes and lymphocytes were distinguished on the basis of dual scatter parameters. The purity of cell populations gated on the basis of scatter parameters was verified by using FMC32 (CD14) as a monocyte marker and a mixture of OKT3 (CD3) and FMC63 (CD19) as a lymphocyte marker.

The flow cytometric data are presented as dual-parameter plots, in which each dot represents one cell. The horizontal and vertical axes give the fluorescence (or scatter) intensity, on a logarithmic scale. In dual-fluorescence plots horizontal and vertical cursors divide cells into quadrants containing doublenegative, double-positive, or single-positive cells. The cursors are positioned using negative control antibodies. In the case of dual-scatter plots, a region ("gate") is drawn to include only lymphocytes, based on the scatter properties of lymphoid and other blood cells. The accuracy of this region is checked using markers for lymphocytes, monocytes, polymorphs, and erythroid cells.

In vitro activation. For in vitro functional studies, mononuclear cell fractions were isolated from cord or adult blood over Ficoll/hypaque, and cultured in 10 -mL culture-grade roundbottom tubes at $5 \times 10^{6}$ cells $/ \mathrm{mL}, 3 \mathrm{~mL}$ per tube, in RPMI 1640 medium supplemented with antibiotics and $10 \%$ FCS. Stimulating agents were added as described in Results. After culture for various periods (Results), cells were harvested, and the expression of various markers of activation determined by immunofluorescence/flow cytometry as described above.

\section{RESULTS}

\section{Expression of Cytokine Receptors by Lymphocytes}

Controls. Figure 1 shows the dual-scatter distribution for cord and adult cells, and the gates used for analysis of lymphocytes. A two-color analysis using X63, an IgG1 negative control antibody, and CD19 shows the levels of background staining seen for $\mathrm{B}$ and non-B cells.

$\boldsymbol{I L}-\mathbf{A R}$. Figure 1 shows that IL-4 reacts with a subpopulation of $\mathrm{B}$ cells in adult blood and does not stain $\mathrm{T}$ cells. The pattern is similar for cord blood cells, although a smaller proportion of $B$ cells react (Table 2).

$\boldsymbol{I L}-\mathbf{2} \boldsymbol{R}$. IL-2 interacts with lymphocytes through a complex receptor/transducer system with at least three components (12). MAb against p55 (CD25) and p75 (CD122) were available for this study. Figure 2 and Table 2 show that expression of the p55 receptor is much lower on cord than on adult lymphocytes. The population showing the highest intensity of staining for p75, identified as LGL (5), is present in cord blood and is seen as the p75-bright subpopulation that is negative for CD19, CD4, and CD8. Although p75 expression is lower on cord than 

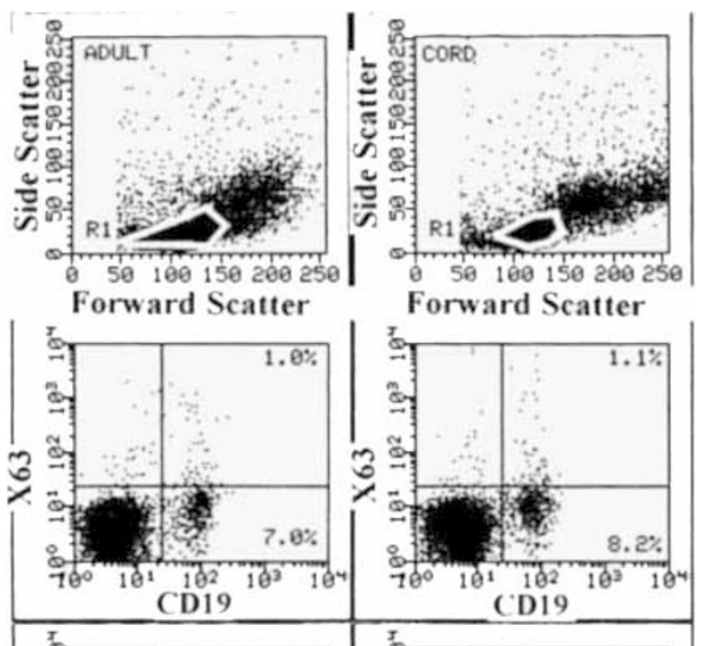

Forward Scatter

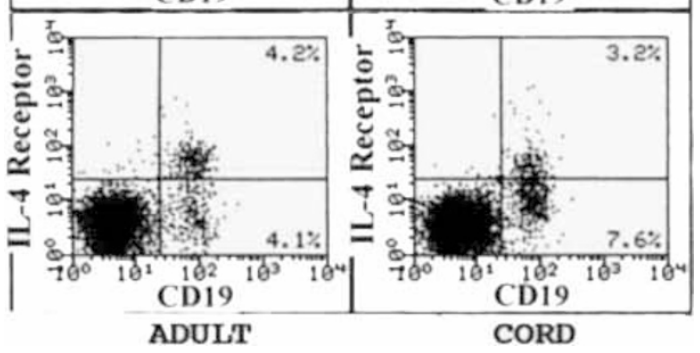

Figure 1. Controls and IL-4R expression. The nature of the flow cytometric plots is explained under Methods. The top two traces show the forward scatter/side scatter distribution and the gate used to select lymphocytes for analysis. Similar gates were used for all the experiments shown in Figs. 1-6. The middle row of traces shows X63, the negative control IgG1 antibody, plotted against the B cell marker CD19. Results for controls of other isotypes were similar and are not shown; these negative controls may be used for comparison with the antibodies used in Figs. 1-6. The bottom row shows IL-4R (vertical axis) against CD19. Percentages indicated in the upper and lower right quadrants indicate the percentage of the total lymphoid population (i.e. the cells within the region outlined in the dual scatter plot) which fall in that particular quadrant. Cells in the upper right quadrant co-express the lineage marker and the cytokine receptor, whereas cells in the lower right quadrant express the lineage marker but do not express the cytokine receptor. For each plot, the adult blood (left column) is compared with cord blood (right column). The data in this and the other figures derive from individual, representative samples; accumulated data and statistical analysis of differences between cord and adult blood are in Table 2 .

adult $\mathrm{B}$ cells, the difference is significant only for $\mathrm{T}$ cells (Fig. 2 and Table 2).

$\boldsymbol{I L}-\mathbf{6 R}$. Although best known as B cell differentiation factor, IL-6 also activates T lymphocytes (13), and MAb to the IL-6 receptor binds primarily to $\mathrm{CD} 4$ cells in adult blood (1). Figure 3 and Table 2 show that cord cells express somewhat lower levels of IL-6R than adult cells.

The IL-6R (p80) associates with a gp130 molecule involved in signal transduction for IL- 6 and a number of other cytokines (14). This molecule is expressed also primarily on CD4 cells in adult blood (Fig. 3). Figure 3 shows that p80 and gp130 are expressed on cord cells, although at generally lower levels.

TNFR. There are two independent TNFR, p55 and p75. Antibodies against the $\mathrm{p} 55$ receptor did not stain cord or adult lymphocytes (Fig. 4). p75 expression was detected on a proportion of adult lymphocytes, including $\mathrm{CD} 4, \mathrm{CD} 8$, and $\mathrm{B}$ cells. Staining was reduced in cord cells compared with adult cells (Fig. 4 and Table 2).
Table 2. Statistical analysis of differences between adult and cord lymphocytes in expression of cytokine receptors

\begin{tabular}{lcccc} 
& \multirow{2}{*}{$\begin{array}{c}\text { Cell } \\
\text { Receptor }\end{array}$} & \multicolumn{2}{c}{ Mean \pm SD $(n)$} & \\
\cline { 2 - 4 } population & Cord & Adult & $p$ \\
\hline IL-4 & B & $29 \pm 8(12)$ & $50 \pm 9(10)$ & 0.0001 \\
IL-2 (p55) & CD4 T & $25 \pm 11(12)$ & $64 \pm 13(17)$ & 0.0001 \\
IL-2 (p55) & CD8 T & $5 \pm 3(10)$ & $27 \pm 9(10)$ & 0.0001 \\
IL-2 (p55) & B & $29 \pm 10(12)$ & $71 \pm 11(17)$ & 0.0001 \\
IL-2 (p75) & CD4 T & $16 \pm 12(11)$ & $42 \pm 20(13)$ & 0.001 \\
IL-2 (p75) & CD8 T & $57 \pm 14(10)$ & $73 \pm 11(10)$ & 0.01 \\
IL-2 (p75) & B & $19 \pm 15(12)$ & $23 \pm 15(13)$ & NS \\
IL-6 & CD4 T & $58 \pm 31(11)$ & $87 \pm 9(13)$ & 0.01 \\
IL-6 (gp130) & CD4 T & $60 \pm 33(11)$ & $75 \pm 9(10)$ & NS \\
TNFRp75 & CD4 T & $35 \pm 20(12)$ & $62 \pm 15(14)$ & 0.001 \\
TNFRp75 & CD8 T & $42 \pm 19(11)$ & $64 \pm 19(12)$ & 0.02 \\
TNFRp75 & B & $23 \pm 20(12)$ & $61 \pm 18(15)$ & 0.0001 \\
IL-7 & CD4 T & $96 \pm 1(11)$ & $98 \pm 2(11)$ & 0.01 \\
IL-7 & CD8 T & $66 \pm 9(11)$ & $73 \pm 9(10)$ & NS \\
IFN- $\gamma$ & CD4 T & $37 \pm 16(11)$ & $50 \pm 20(11)$ & NS \\
IFN- $\gamma$ & CD8 T & $51 \pm 10(10)$ & $66 \pm 17(10)$ & 0.03 \\
IFN- $\gamma$ & B & $84 \pm 11(12)$ & $87 \pm 10(12)$ & NS \\
\hline & & & &
\end{tabular}
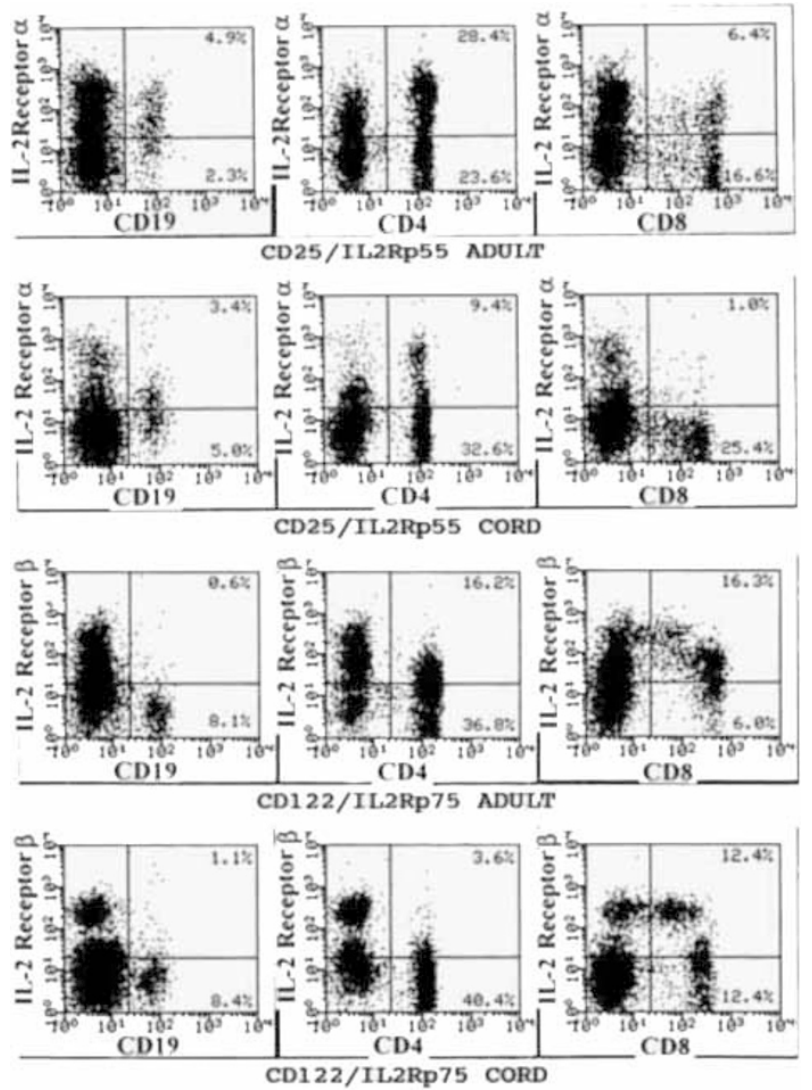

Figure 2. IL-2R expression in cord and adult blood. The top two rows show IL-2Rp55 chain (CD25) whereas the bottom two rows show IL-2Rp75 (CD122); data for cord blood are shown below corresponding adult blood data. Each panel represents dual fluorescence distributions with the IL- $2 R$ on the vertical axis plotted against the lymphocyte subset marker (CD19, CD4, or CD8) on the horizontal axis. For further explanation of the plots, see caption to Fig. 1.

$\boldsymbol{I L}-\mathbf{7 R}$. Antibody against the IL-7R stained the majority of CD4 cells and a proportion of CD8 cells and failed to stain most $\mathrm{B}$ cells in adult blood. The patterns were very similar for cord blood (Fig. 5), although staining intensities were somewhat lower. 

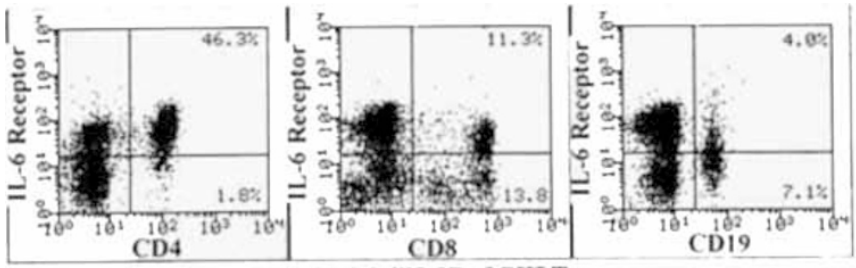

CD126/IL6R ADULT
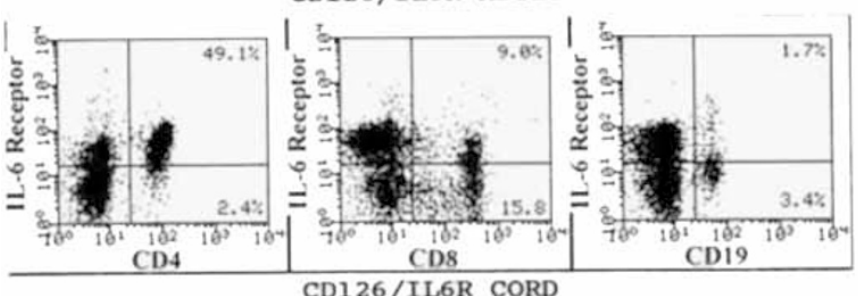

CD126/IL6R CORD
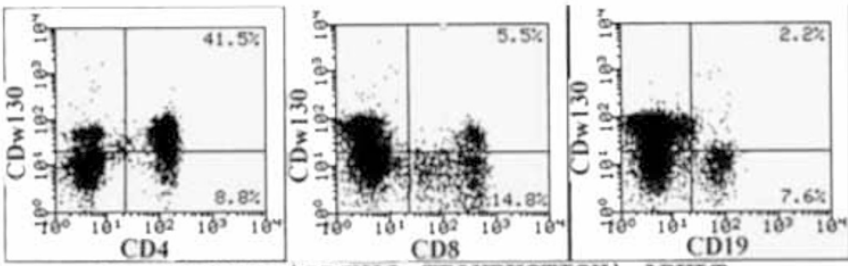

CDw130/IL6
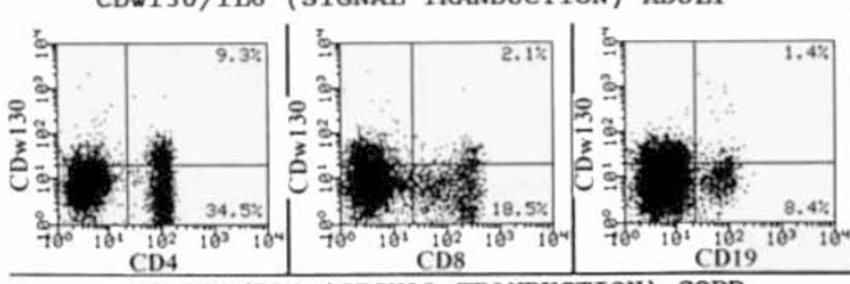

CDW130/IL6 (SIGNAL TRANDUCTION) CORD

Figure 3. IL-6R expression in cord and adult blood. The top two rows show IL-6R (p80, CD126) whereas the bottom two rows show IL-6R signal transducing chain (gp130, CDw130); data for cord blood are shown below corresponding adult blood data. Each panel represents dual fluorescence distributions with the IL-6R on the vertical axis plotted against the lymphocyte subset marker (CD4, CD8, or CD19) on the horizontal axis. For further explanation of the plots, see caption to Fig. 1 .

IFN- $\gamma$ receptor. Antibody against IFN- $\gamma$ receptor stained $\mathrm{T}$ and $\mathrm{B}$ cells in adult blood (Fig. 6). Although all $\mathrm{B}$ cells stained, CD4 and CD8 cells showed weak staining, which overlapped the negative control but did not resolve into a positive and a negative peak, suggesting that all $\mathrm{T}$ cells show very low level expression. In cord blood cells, T cell staining was weaker, but B cell staining was as strong as on adult cells.

\section{Expression of Cytokine Receptors by Monocytes}

Figure 7 shows the staining pattern of monocytes from cord and adult blood with the cytokine receptor antibodies. Cord monocytes express both chains of the IL-2R, as well as receptors for IL-4, TNF (the p75 receptor more strongly than the p55 receptor), and IFN- $\gamma$. Although monocytes from both cord and adult blood expressed IL-6R they did not express the gp130 chain, suggesting the $\mathrm{IL}-6 \mathrm{R}$ is nonfunctional. Two sets of cord and adult samples were compared; receptor expression was consistent, but there were no major consistent differences between cord and adult monocytes in terms of cytokine receptor expression.
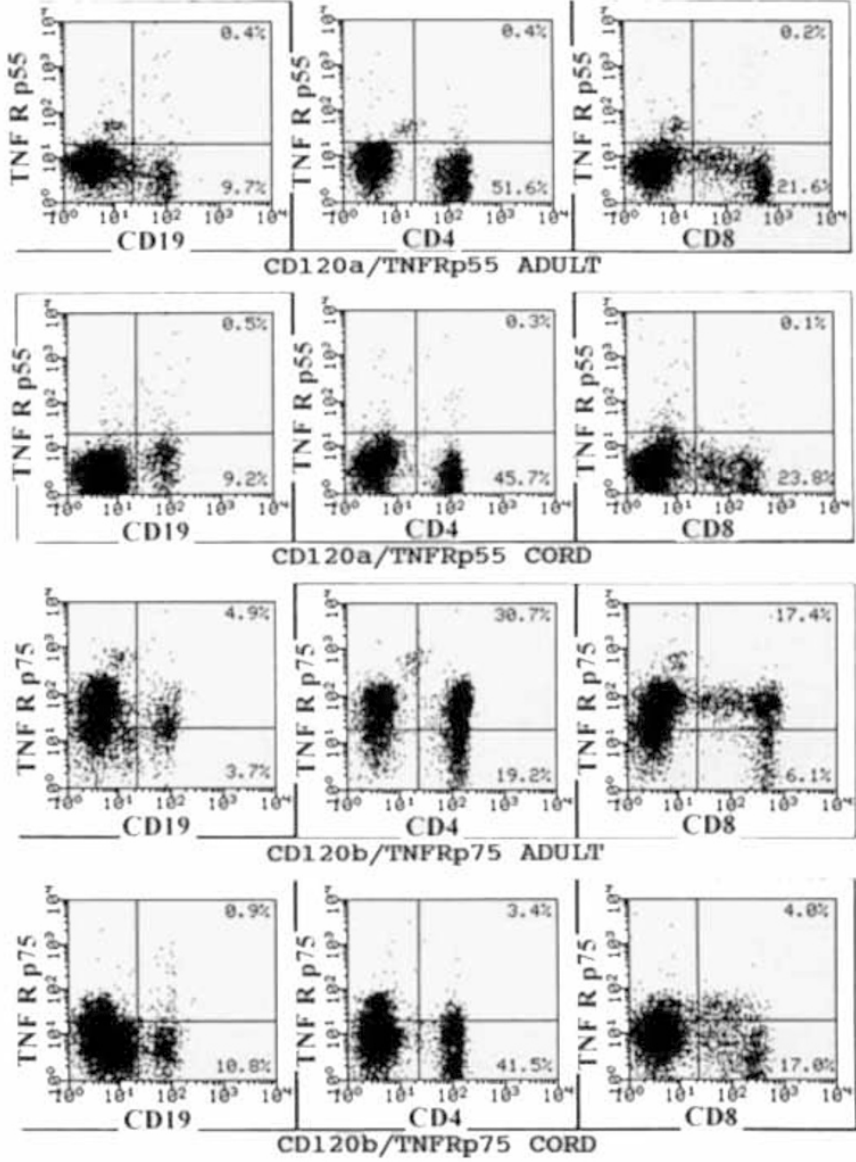

Figure 4. TNFR expression in cord and adult blood. The top two rows show TNFRp55 (CD120a) whereas the bottom two rows show TNFRp75 (CD120b); data for cord blood are shown below corresponding adult blood data. Each panel represents dual fluorescence distributions with the TNFR on the vertical axis plotted against the lymphocyte subset marker (CD19, CD4, or CD8) on the horizontal axis. For further explanation of the plots, see caption to Fig. 1.

\section{In Vitro Lymphocyte Cultures}

Responsiveness to IL-4 in vitro. To determine whether the IL-4R on cord B cells is functional, adult and cord lymphocytes were cultured with IL-4 at 25 and $100 \mathrm{U} / \mathrm{mL}$ for $24 \mathrm{~h}$. The cells were then stained for expression of MHC class II antigen, CD23, and surface Ig, which are all up-regulated by IL-4 in adult cells. Cells were stained simultaneously with CD19, to allow analysis of marker expression specifically on B cells. Table 3 shows the results of one experiment; a replicate experiment on different blood samples gave similar results. CD23, MHC class II, and surface IgM and D were all upregulated in cord, as well as adult blood B cells.

Regulation of receptors by activation stimuli. Cord and adult blood cells were cultured with PHA at $5 \mu \mathrm{g} / \mathrm{mL}$, a concentration demonstrated by preliminary experiments to induce blastogenesis and proliferation. After $3 \mathrm{~d}$, the expression of a number of markers was examined. PHA led to blastogenesis, which was seen as increased forward light scatter in flow cytometry (Fig. 8). There was a major increase in the expression of the p55 chain of the IL-2R, and a smaller increase in the expression of the p75 chain of the IL-2R and the p75 TNFR, in both cord and adult cells (Fig. 9). 

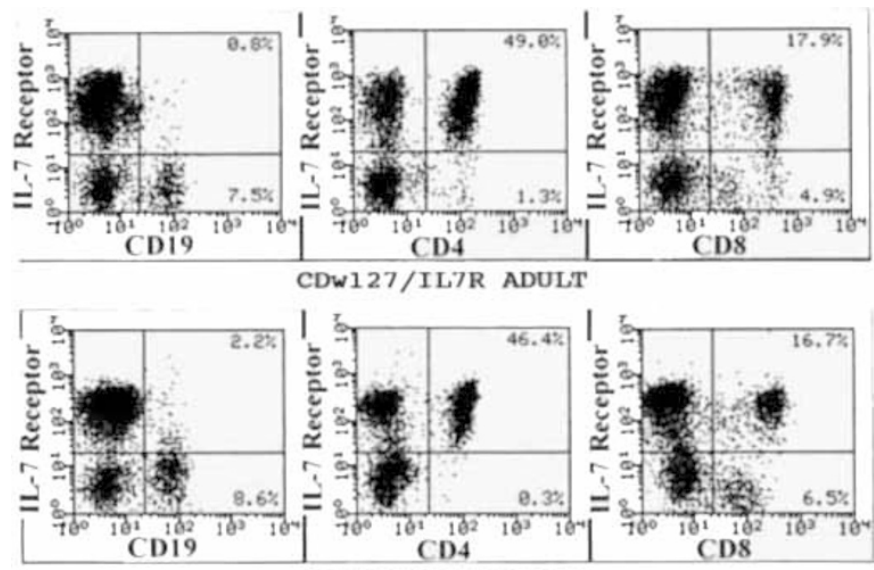

CDW127/IL7R CORD

Figure 5. IL-7R expression in cord and adult blood. The top row shows IL-7 (CDw127) expression on adult blood, whereas the bottom row shows data for cord blood. Each panel represents dual fluorescence distributions with the cytokine receptor on the vertical axis plotted against the lymphocyte subset marker $(C D 19, C D 4$, or $\mathrm{CD} 8)$ on the horizontal axis. For further explanation of the plots, see caption to Fig. 1.
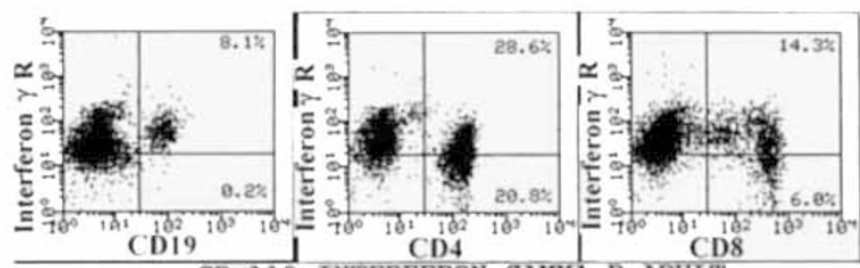

\section{CDw11}

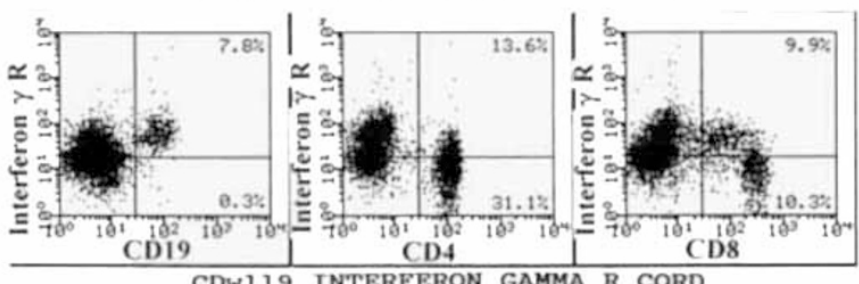

CDW119 INTERFERON GAMMA R CORD

Figure 6. INF- $\gamma$ receptor expression in cord and adult blood. The top row shows adult whereas the bottom row shows cord blood; each panel represents dual fluorescence distributions with the INF- $\gamma$ receptor on the vertical axis plotted against the lymphocyte subset marker (CD19, CD4, or CD8) on the horizontal axis. For further explanation of the plots, see caption to Fig. 1.

\section{DISCUSSION}

Cytokine receptors are sometimes present at very low concentrations (10-1000 molecules per cell), and can be functional at these concentrations $(1-7)$. These low levels require the use of specialized high sensitivity methods if the receptors are to be detected adequately $(1-4,6-7)$. Using such high sensitivity methods, receptor expression was lower on cord than on adult lymphocytes, for most of the cytokines studied. However, there was a large range of values for some of the receptors, so that differences in mean values were statistically significant for only a limited number of comparisons (Table 2).

The p55 chain of the IL-2R has a short half-life (15), and its expression therefore suggests recent or ongoing activation. The low levels of p55 on cord cells fits with their anticipated lack of immune stimulation. The p75 chain of the IL-2R, on the other hand, is expressed constitutively on adult cells and is

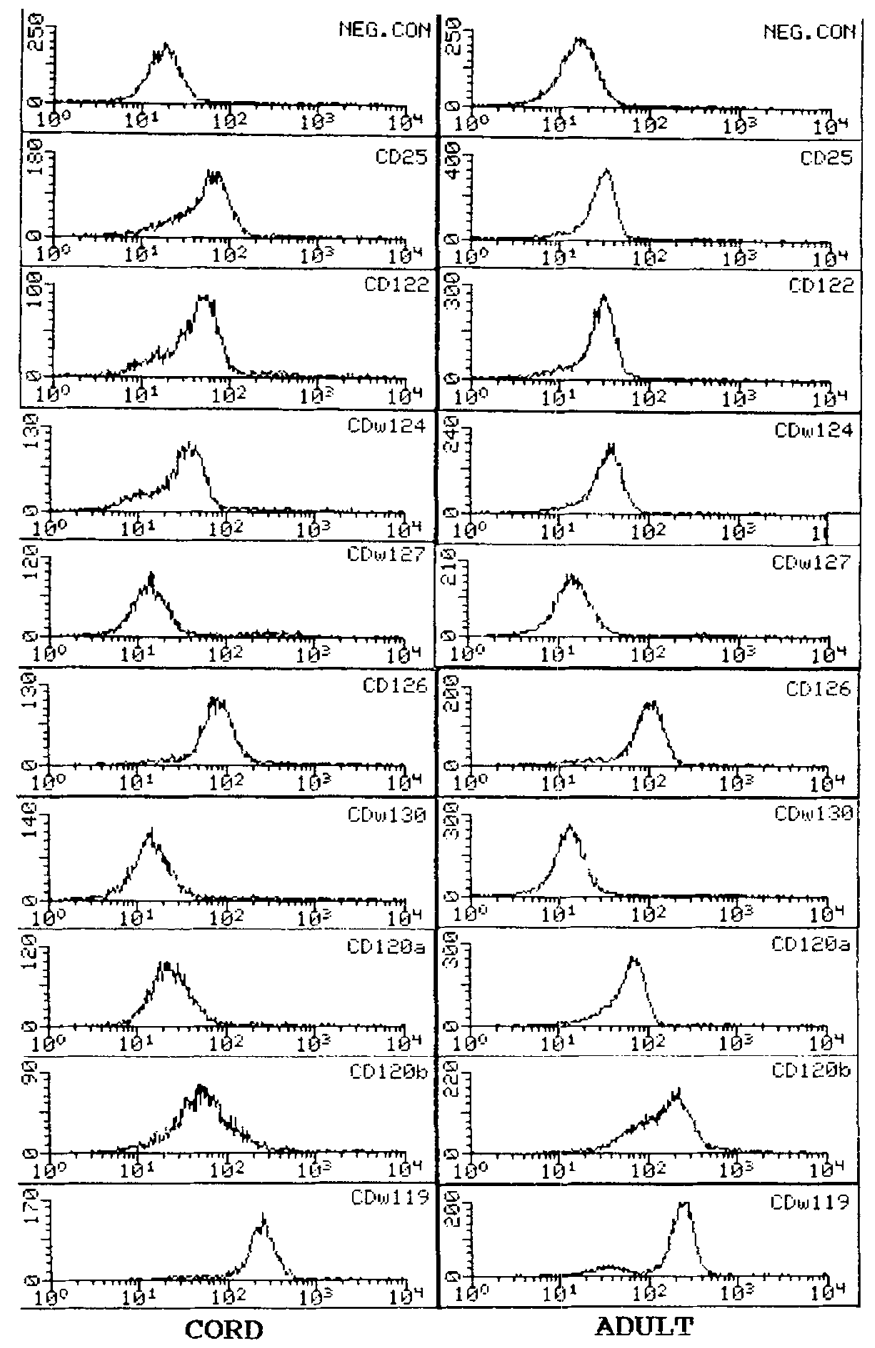

Figure 7. Cytokine receptor expression by monocytes. Monocytes were selected using dual scatter parameters, and the purity of the population in the gate was checked using a monocyte marker (CD14), which showed the population to contain 97 and $95 \%$ monocytes (adult and cord samples, respectively) and a mixture of $\mathrm{T}$ and B lymphocyte markers (CD3 + CD19), which showed 4 and $5 \%$ lymphocytes (adult and cord samples, respectively) contaminating the gated population. The traces show fluorescence histograms for the cytokine receptor antibodies, compared with a negative control, for cord (left column) and adult (right column) monocytes. The receptors identified by each CD are listed in Table 1.

relatively refractory to up-regulation $(16-18)$. The relative lack of p75 on cord $\mathrm{T}$ cells (but not on LGL) suggests that this a feature of the relative immaturity of the cord cells. p75 expression would be expected to rise in the first months of life as the immune system achieves competence, and this is one parameter which might repay examination in patients with immune deficiencies. The same may be said for the IL-4R on B cells and for the IL-6R and the p75 TNFR.

In vitro activation experiments showed that IL-2R and TNFR, which are expressed at relatively low levels on cord cells, could be up-regulated by activation. These experiments show that cord cells can respond to broadly acting activation stimuli, but are not intended to mimic the maturation events that would go on in the neonate.

The $\mathrm{B}$ cells of cord blood have a phenotype suggesting a relatively activated state $(19-21)$ and appear to belong to the 
Table 3. Effect of 24-h culture in the presence of IL-4 on the expression of $C D 23, M H C$ class II, and surface Ig: comparison of cord and adult blood $B$ cells

\begin{tabular}{|c|c|c|c|c|c|c|}
\hline \multicolumn{7}{|c|}{ Mean fluorescence intensities* } \\
\hline \multirow[b]{2}{*}{ Marker } & \multicolumn{3}{|c|}{$\begin{array}{c}\text { Cord blood } \\
\text { (units IL-4/mL): }\end{array}$} & \multicolumn{3}{|c|}{$\begin{array}{c}\text { Adult blood } \\
\text { (units IL-4/mL): }\end{array}$} \\
\hline & 0 & 25 & 100 & 0 & 25 & 100 \\
\hline CD23 & 21 & 39 & 54 & 35 & 65 & 71 \\
\hline $\lg \mathrm{D}$ & 202 & 837 & 403 & 163 & 227 & 195 \\
\hline Negative control & 5 & 5 & 5 & 2 & 3 & 2 \\
\hline MHC class IIt & 1940 & 2204 & 2284 & 2608 & 2767 & 3336 \\
\hline $\operatorname{Ig} M \dagger$ & 565 & 1268 & 1229 & 147 & 385 & 310 \\
\hline Negative control $\dagger$ & 2 & 2 & 2 & 1 & 1 & 1 \\
\hline
\end{tabular}

* Mean fluorescence intensity (MFI) recorded for the positive peak, except in the case of negative controls and CD23, when the MFI is given for the whole population, because two populations were not completely resolved.

$\dagger$ Read at reduced amplifier voltage to keep peak on scale.
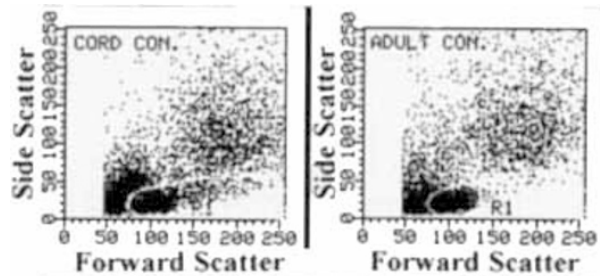

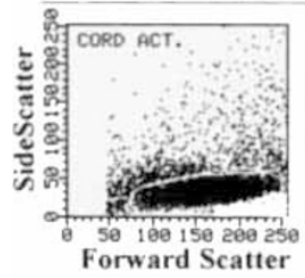

CORD

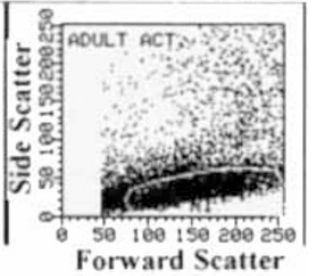

ADULT
Figure 8. Blastogenesis induced by culture in PHA. The dual-scatter parameter plots show $90^{\circ}$ scatter (SSC, vertical axis) against low angle scatter (FSC, horizontal axis) for cord (left) and adult (right) blood lymphocytes. The dual scatter patterns are shown for cells cultured for $3 \mathrm{~d}$ in the presence (lower panels) and absence (upper panels) of PHA.

CD5 subset $(19,20)$, which is a relatively rare B cell in adult blood. The selective expression of receptors for some of the cytokines that can act on B cells (IFN- $\gamma$ ) and the relative absence of others (IL-4, IL-2, IL-6, and TNF) suggests that cord $\mathrm{B}$ cells are activated, but represent a functionally distinct subset, in accord with the CD5 hypothesis. In the case of the IL-4R, there was significant receptor expression on cord cells, although lower than on adult B cells. Functional studies showed that cord cells express a functional receptor, capable of responding to IL-4 to give phenotypic changes similar to those seen in adult cells.

The presence of IL-7R on cord lymphocytes is in agreement with the reported role for this cytokine in lymphocyte development (22). Monocytes expressed a cytokine receptor profile that was broadly similar to that seen on adult cells, suggesting that neonatal monocytes are functionally mature. The essentially normal levels of IL-2Rp75 on LGL in cord blood suggests that LGL may also be functionally mature.

The selective expression, by some neonatal cell types, of adult levels of some cytokine receptors, whereas others are

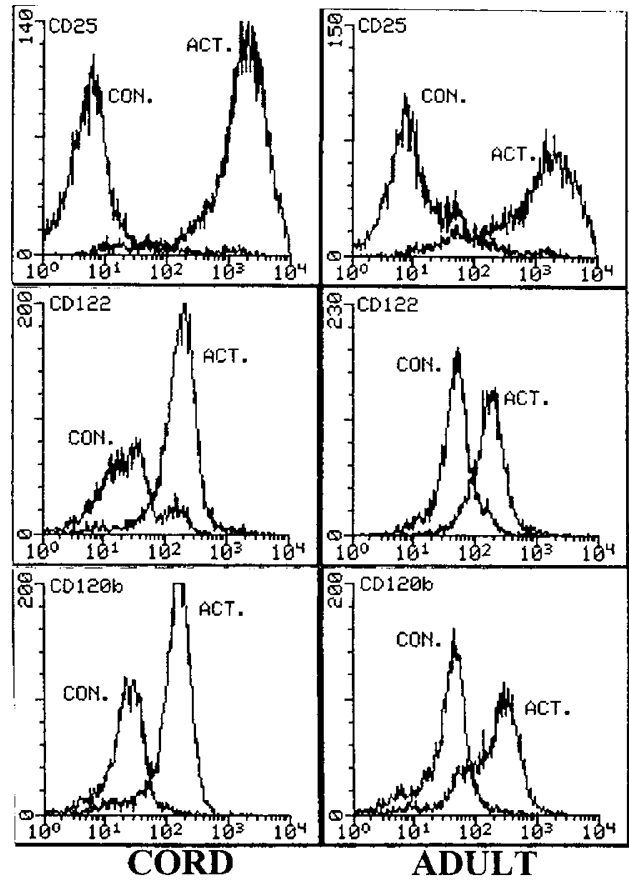

Figure 9. Activation by PHA: effect on cytokine receptor expression. The cell populations examined in Figure 8 were tested for expression of CD25 (IL2Rp55, top row), CD122 (IL-2Rp75, middle row), and CD120b (p75TNFR, bottom row). Results for cord cells are shown in the left column, and adult cells are shown in the right column. In each block the traces are shown for cells cultured in the presence (labeled ACT.) and absence (labeled CON.) of PHA.

expressed at much reduced levels, indicates a degree of complexity in the regulation of cytokine receptors during maturation. Different cell types regulate their receptors differently, perhaps in tune with the functional requirements of the developing immune system.

Acknowledgments. The authors thank the donors of the $\mathrm{MAb}$ against cytokine receptors (Table 1) for making there reagents available. Helen Weedon is thanked for help with the figures and general technical assistance. The staff of the Lyell McEwin Hospital, and Gordon Howarth of the Child Health Research Institute, are thanked for their help in obtaining cord blood samples.

\section{REFERENCES}

1. Zola H, Flego L 1992 Expression of interleukin-6 receptor on blood lymphocytes without in vitro activation. Immunology 76:338-341

2. Zola H, Mantzioris BX, Webster J, Kette FE 1989 Circulating human T and B lymphocytes express the p55 interleukin-2 receptor molecule (TAC, CD25). Immunol Cell Biol 67:233-237

3. Jackson AL, Matsumoto H, Janzen M, Maino V, Blidy A, Shye S 1990 Restricted expression of p55 IL-2 receptor (CD25) on normal T cells. Clin Immunol Immunopathol 54:126-133

4. Zola H, Purling RJ, Koh LY, Tsudo M 1990 Expression of the p70 chain of the IL-2 receptor on human lymphoid cells: Analysis using a monoclonal antibody and high-sensitivity immunofluorescence. Immunol Cell Biol 68:217-224

5. Tsudo M, Goldman CK, Bongiovanni KF, Chan WC, Winton EF, Yagita M, Grimm EA, Waldmann TA 1987 The P75 peptide is the receptor for interleukin 2 expressed on large granular lymphocytes and is responsible for the interleukin 2 activation of these cells. Proc Natl Acad Sci USA 84:5394-5398

6. Zola H, Flego L, Weedon H 1993 Expression of IL-4 receptor on human T and B lymphocytes. Cell Immunol 150:149-158

7. Zola H, Flego L, Weedon H 1993 Expression of membrane receptor for tumour necrosis factor on human blood lymphocytes. Immunol Cell Biol 71:281-288

8. Noguchi M, Yi H, Rosenblatt HM, Filipovich AH, Adelstein S, Modi WS, McBride OW, Leonard WJ 1993 Interleukin-2 receptor gamma chain mutation results in $\mathrm{X}$-linked severe combined immunodeficiency in humans. Cell 73:147-157 
9. Schlossman SF, Boumsell L, Gilks W, Harlan IM, Kishimoto T, Morimoto C, Ritz I, Shaw S, Silverstein RL, Springer TA, Tedder TF, Todd RF 1994 CD antigens 1993. Immunologist 2:28-29

10. Leucocyte Typing VI: White Cell Differentiation Antigens. Oxford: Oxford University Press, 1994

11. Zola H, Flego L, Wong YT, Macardle PJ, Kenney JS 1993 Direct demonstration of membrane IL-1 $\alpha$ on the surface of circulating B lymphocytes and monocytes. J Immunol 150:1755-1762

12. Taniguchi T, Minami Y 1993 The IL-2/IL-2 receptor system: A current overview. Cell 73:5-8

13. Uyttenhove C, Coulie PG, Van Snick J $1988 \mathrm{~T}$ cell growth and differentiation induced by interleukin-HP1/IL-6, the murine hybridoma/plasmacytoma growth factor. J Exp Med 167:1417-1427

14. Taga T, Kishimoto T 1992 Cytokine receptors and signal transduction. FASEB J 6:3387-3396

15. Sayar D, Ketzinel M, Gerez L, Silberberg C, Reshef A, Kaempfer R 1990 Expression of the human IL-2 receptor on lymphocytes involves rapid turnover of its p55 $\alpha$-subunit (Tac)1. J Immunol 145:2946-2949

16. Moire N, Calvo CF, Metivier D, Perrot JY, Vaquero C, Hatakeyama M, Senik A 1990 Role of interleukin 2 receptor beta chain in initiating anti-CD3 and interleukin 2 -induced proliferation of human resting T cells. Eur J Immunol 20:1981-1987

17. Waldmann TA 1989 The multi-subunit interlcukin-2 receptor. Annu Rev Biochem 58:875-911

18. Zola H, Weedon H, Thompson GR, Fung MC, Ingley E, Hapel AJ 1991 Expression of IL-2 receptor p55 and p75 chains by human B lymphocytes: Effects of activation and diffcrentiation. Immunology 72:167-173

19. Erkeller Yuksel FM, Deneys V, Yuksel B, Hannet I, Hulstaert F, Hamilton C, Mackinnon H, Stokes LT, Munhyeshuli V, Vanlangendonck F, et al. 1992 Agerclated changes in human blood lymphocyte subpopulations. J Pcdiatr 120:216-222
20. Durandy A, Thuillier L, Forvcille M, Fischer A 1990 Phenotypic and functional characteristics of human newborns' B lymphocytes. J Immunol 144:60-65

21. Small TN, Keever C, Collins N, Dupont B, O'Reilly RJ, Flomenberg N 1989 Characterization of $\mathrm{B}$ cells in severe combined immunodeficiency disease. Hum Immunol 25:181-193

22. Saeland S, Duvert V, Pandrau D, Caux C, Durand I, Wrighton N, Wideman J, Lee F, Banchereau J 1991. Interleukin-7 induces the proliferation of normal human B-cell precursors. Blood 78:2229-2238

23. Rubin LA, Kurman CC, Biddison WE, Goldman ND, Nelson DL 1985 A monoclonal antibody $7 \mathrm{G} 7 / \mathrm{B} 6$ binds to an epitope on the human interleukin-2 (IL-2) receptor that is distinct from that recognized by IL-2 or anti-Tac. Hybridoma 4:91-102

24. Tsudo M, Kitamura F, Miyasaka M 1989 Characterization of the interleukin 2 receptor beta chain using three distinct monoclonal antibodies. Proc Natl Acad Sci USA 86:1982-1986

25. Fanslow WC, Spriggs MK, Rauch CT, Clifford KN, Macduff BM, Ziegler SF, Schooley KA, Mohler KM, March CJ, Armitage RJ 1993 Identification of a distinct low affinity receptor for human interleukin-4 on pre-B cells. Blood 81:2998-3005

26. Hirata Y, Taga T, Hibi M, Nakano N, Hirano T, Kishimoto T 1989 Characterization of IL- 6 receptor expression by monoclonal and polyclonal antibodies. J Immunol 143:2900-2906

27. Taga T, Narazaki M, Yasukawa K, Saito T, Miki D, Hamaguchi M, Davis S, Shoyab $M$, Yancopoulos GD, Kishimoto T 1992 Functional inhibition of hematopoietic and neurotrophic cytokines by blocking the interleukin 6 signal transducer gp130. Proc Natl Acad Sci USA 89:10998-11001

28. Brockbaus M, Schoenfeld H-J, Schlaeger E-J, Hunziker W, Lesslauer W, Loetscher H 1990 Identification of two types of tumor necrosis factor receptors on human ccll lines by monoclonal antibodies. Proc Nat\} Acad Scj USA 87:3127-3131 